\title{
PEMBUATAN GAME EDUKASI "ENGLISH FOR FUN" UNTUK ANAK KELAS 1-2 SD BERBASIS ANDROID MENGGUNAKAN UNITY 3D
}

\author{
Rudi Hartono \\ Fakultas MIPA, Program Studi D3 Teknik Informatika \\ Universitas Sebelas Maret \\ Email: rudi.hartono@staff.uns.ac.id \\ Agus Purnomo \\ Fakultas MIPA, Program Studi D3 Teknik Informatika \\ Universitas Sebelas Maret \\ Email: agus.purnomo@staff.uns.ac.id \\ Nughthoh Arfawi Kurdhi \\ Fakultas MIPA, Program Studi Matematika \\ Universitas Sebelas Maret \\ Email: arfa@mipa.uns.ac.id \\ Intan Hikmah Firdiana \\ Fakultas MIPA, Program Studi D3 Teknik Informatika \\ Universitas Sebelas Maret
}

\begin{abstract}
ABSTRAK
Perkembangan teknologi yang semakin pesat saat ini, harus dapat dimanfaatkan dalam setiap sisi kehidupan manusia yang bertujuan agara teknologi tersebut berguna, membantu dan mempermudah kehidupan manusia. Peranan teknologi tidak hanya dipandang pada kehidupan orang dewasa, namun alangkah baiknya teknologi juga dapat berperan dalam kehidupan anak-anak khususnya bidang pendidikan. Teknologi yang akan difokuskan dalam penelitian ini adalah teknologi di smart phone dan android, guna memudahkan anak dalam belajar bahasa inggris sejak dini. Dalam pengembangan aplikasi ini dibuat semudah mungkin dalam pengoprasian dengan penggunaan control drag and drop pada gameplaynya. Game English For Fun dinilai dapat menambah ketertarikan dalam belajar bahasa inggris sesuai dengan survey yang telah dilakukan dengan hasil kuisoner responden, kuisioner dengan pertanyaan “Apakah dengan Game English For Fun dapat lebih mudah dalam belajar Bahasa Inggris?” dihasilkan 48,6\% responden menjawab sangat setuju. Game ini dapat berjalan di perangkat android pada beberapa versi operating system, seperti Jellybean, Kitkat, dan Lollipop. Game Edukasi "English For Fun" yaitu sebagai sarana bermain sekaligus pembelajaran Bahasa Inggris untuk anak-anak, khusunya anak kelas 1-2 Sekolah Dasar agar mengenal lebih banyak nama-nama Alfabet, Angka, Buah, Hewan, Transportasi, Bangun Datar, Anggota Tubuh Manusia dan Warna dalam Bahasa Inggris.
\end{abstract}

Kata kunci: game, android, unity $3 D$, edukasi bahasa inggris.

\begin{abstract}
Increasingly rapid technological development today, should be used in every side of human life which aims to profess these technologies are useful, helpful and facilitate human life. The role of technology is not only seen in an adult's life, but it is good technology can also play a role in the lives of children, especially in education. The technology will be focused in this research is the technology in smart phones and android, in order to facilitate the child in learning English from an early age. In the development of this application is made as easy as possible in operational control with the use of drag and drop on the gameplay. English Games For Fun assessed can add interest in learning English according to the survey that was conducted with the results of the questionnaire respondents, the questionnaire with the question "Are the English Game For Fun can be easier to learn English?" Generated $48.6 \%$ of respondents answered very agree. This game can be run on an android device on some versions of the operating system, such as Jellybean, Kitkat and Lollipop. Game Education "English for Fun" is as a means of learning English at the same time play for children, especially children grade 1-2 elementary school in order to learn more about the names of the Alphabet, Numbers, Fruits, Animals, Transportation, Bangun Datar, Limbs humans and Colors in English.
\end{abstract}

Keywords: game, android, unity 3D, education english. 


\section{PENDAHULUAN}

Dalam proses pembelajaran ada beberapa aspek pendukung, salah satu aspek yang sangat penting adalah teknologi pembelajaran. Teknologi pembelajaran menurut Silber adalah pengembangan sistem komponen pembelajaran serta pengelolaan usaha pengembangan secara sistematik, dengan tujuan untuk memecahkan masalah belajar [1]. Untuk memecahkan masalah belajar dapat dikombinasikan dengan teknologi yang saat ini baru menjadi tren salah satunya adalah teknologi smart phone.

Saat ini penggunaan smart phone di Indonesia terus meningkat, sebuah lembaga riset indonesia merupakan peringkat ke lima terbesar didunia dalam pengguna smart phone [2], dalam sebuh smart phone tidak terlepas dari aplikasi game. Setiap tahun jumlah pemain game di Indonesia terus menerus bertambah, bahkan saat ini Indonesia mengalami pertumbuhan pemain game hingga 33\% setiap tahunnya, dan sampai tahun 2012 di Indonesia terdapat tiga puluh juta pengguna game online dengan rata-rata umur pengguna antara 17 tahun hingga 40 tahun. Hasil penelitian Tri Wulan wijayanti [3], menyimpulkan bahwa salah satu tujuan atau motif yang melatar belakangi penggunaan game online adalah sebagai hiburan. Dengan fakta perkembangan smart phone dan game dapat digabungkan untuk memecahkan masalah belajar.

Pembelajaran bahasa terutama bahasa inggris pada tingkat SD, pelajaran bahasa Inggris sudah diajarkan untuk melatih dasar-dasarnya. Bagi sebagian besar murid di Sekolah Dasar, mata pelajaran bahasa Inggris bisa jadi merupakan mata pelajaran baru dan sulit. Dengan latar belakang yang ada dalam penelitian ini akan melakukan pengembangan teknologi pembelajaran untuk memecahkan masalah belajar bahasa inggris untuk siswa sekolah dasar. Dengan memanfaatkan perkembangan teknologi smart phone dan perkembangan game.

\section{METODE PENELITIAN}

Metodologi penelitian sangat diperlukan untuk mendapatkan bukti kebenaran suatu konsep dan teori yang diperoleh serta untuk menemukan dan menguji suatu pengetahuan, metodologi penelitian yang digunakan dalam pembuatan game edukasi dan pembuatan game edukasi adalah sebagai berikut :

1) Kepustakaan, pengumpulan data-data dari buku ataupun ebook.

2) Observasi, pengumpulan data dengan cara pengamatan langsung ke objek yang diteliti yaitu anak-anak.

3) Wawancara, ini adalah metodologi yang dilakukan dengan cara tanya-jawab langsung dengan guru maupun anak-anak.

4) Analisis, penelitian ini dibutuhkan beberapa alat bantu yang mendukung dalam peracangan game edukasi, yang terbagi menjadi 2 bagian yaitu perangkat keras (hardware) dan pernagkat lunak (software).

5) Perancangan, perancangan ini merancang tata letak game yang dibutuhkan untuk mendukung perancangan game edukasi.

6) Pemrograman, penulisan kode program yang akan dieksekusi oleh computer.

7) Uji Coba, melakukan pengujian hasil pembuatan game edukasi yang telah dibuat secara keseluruhan sebelum diimplementasikan dan kemudian melakukan jejak pendapat tentang hasil penelitian.

8) Implementasi, pada tahap ini, program atau aplikasi di implementasikan sebagai akhir pembuatan perangkat lunak atau menerapkan uji coba pada objek penelitian..

\subsection{Tinjauan Pustaka}

Tinjauan pustaka dalam pembuatan Game English For Fun, mengambil dari dua artikel. Karya tulis tersebut ditulis oleh Dipa Ayu Sahlinapada tahun 2015 dengan judul Pembuatan Game Edukasi "Puzzle Qur'an Juz 30" Berbasis Android Menggunakan Unity 3D. Karya tulis ilmiah kedua yang ditulis oleh Dwi Saputra pada tahun 2015 dengan judul Game "Bahasa Inggris Anak" Berbasis Android Menggunakan Construct 2 [4].

Berdasarkan tinjauan pustaka, maka dapat disimpulkan bahwa perbedaan dengan yang buat dengan judul "Game English For Fun" yaitu :

1) Terdapat pembelajaran bahasa inggris yang sesuai untuk anak yaitu dengan membaca Angka, Buah, Alfabet, Hewan, Bangun Datar, Anggota Tubuh Manusia, Transportasidan Warna.

2) Gambar yang menarik anak untuk terus bermain dan belajar lewat aplikasi ini.

3) Penggunaan control drag and drop pada gameplaynya.

4) Disediakan audio sebagai media pembelajaran.

5) Suara yang digunakan untuk mengeja jelas dan benar pengejaannya.

6) Audio bisa diulang-ulang hingga anak mengerti.

7) Fitur random scene. 


\subsubsection{Dasar Teori}

Teori tentang game banyak dikemukakan oleh para ahli, diantaranya adalah menurut [5][6], game merupakan permainan komputer yang dibuat dengan teknik dan metode animasi. Jika ingin mendalami penggunaan animasi haruslah memahami pembuatan game atau jika ingin membuat game, maka haruslah memahami teknik dan metode animasi, sebab keduanya saling berkaitan. Sedangkan menurut ahli lainnya yakni [5], game adalah kegiatan yang melibatkan keputusan pemain, berupaya mencapai tujuan dengan dibatasi oleh konteks tertentu (misalnya dibatasi oleh peraturan). Menurut [6], genre game adalah klasifikasi game yang didasari interaksi pemainnya. Game dapat dikelompokkan kedalam beberapa jenis game simulasi, edukasi dan entertainment.

Game dengan jenis edukasi contohnya adalah edugames yang dibuat dengan tujuan spesifik yaitu sebagai alat pendidikan, misalnya game untuk belajar mengenal warna, mengenal huruf dan angka, belajar matematika, dan masih banyak yang lainnya. Pengembang yang membuat game jenis ini harus memperhitungkan berbagai hal agar game ini benar-benar dapat mendidik, menambah pengetahuan, dan meningkatkan ketrampilan pemain yang memainkannya.

Pengujian black-box berusaha untuk menemukan kesalahan dalam beberapa kategori, diantaranya: fungsifungsi yang salah atau hilang, kesalahan interface, kesalahan dalam struktur data atau akses database eksternal, kesalahan performa, kesalahan inisialisasi dan terminasi [7].

Kuisioner (Questionnaires) yaitu sejumlah pertanyaan tertulis yang digunakan untuk memperoleh informasi dari responden dalam arti laporan tentang pribadinya atau hal-hal yang diketahui responden [5].

Struktur navigasi digunakan sebagai penuntun alur sebuah aplikasi multimedia atau dapat pula dianalogikan sebagai diagram alur dalam perancangan bahasa pemrograman. Struktur navigasi berfungsi untuk menggambarkan dengan jelas hubungan dan rantai kerja seluruh elemen yang akan digunakan dalam aplikasi. Dengan penggambaran struktur navigasi, pembuatan sebuah aplikasi dapat sistematis dan mudah. Jenis struktur navigasi dikelompokkan menjadi 4 struktur yang berbeda yaitu linier, hirarki, non linier dan campuran yang mempunyai perbedaan dalam bentuk rangkaiannya.

\section{HASIL DAN PEMBAHASAN}

\subsection{Perancangan Dasar Game}

Game English For Fun ini merupakan game tentang bagaimana cara melengkapi kata dengan puzzle huruf pada game 1 dan mencocokan gambar dengan nama kategori yang telah dipilih pada game 2 . Pada game 1 untuk melengkapi kata ejaan membaca dengan puzzle huruf yang telah dipilih, pemain melakukan drag and drop puzzle huruf yang akan diisikan kedalam kotak kosong yang telah disediakan. Klik "jawab" ketika sudah selesai menjawab. Pada game 2 untuk mencocokan gambar dengan puzzle nama kategori yang telah dipilih, pemain melakukan drag and drop puzzle nama yang akan diisikan kedalam kotak kosong yang telah disediakan. Klik " $\sqrt{ }$ " ketika sudah selesai menjawab.Pada setiap game terdapat 4 tahap permaian, dimana puzzle yang harus dijawab jumlahnya akan semakin banyak.

\subsubsection{Narasi Dan Storyboard}

Perancangan menu-menu yang akan diterapkan dalam game ini dapat terlihat pada gambar. 1

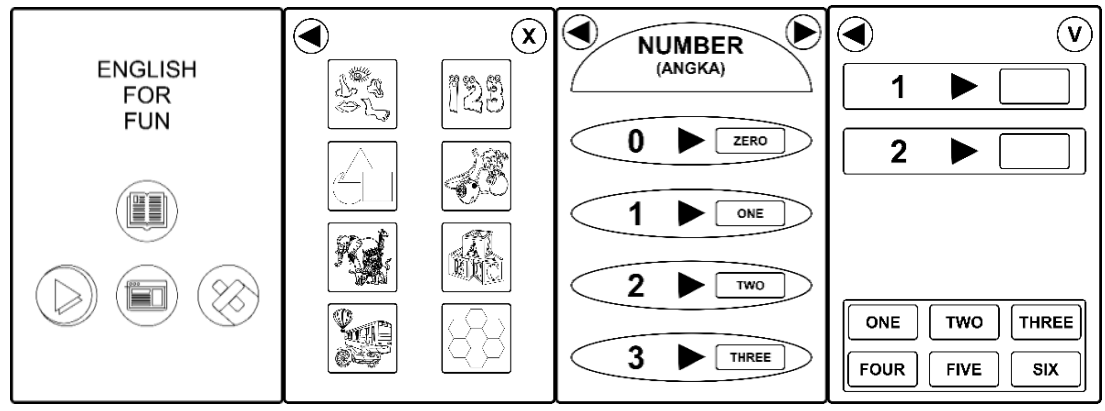

Gambar 1. Perancangan Menu Dalam Game 


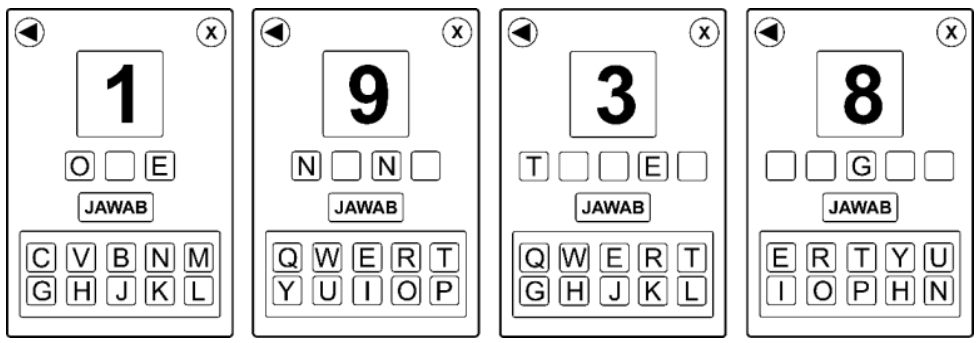

Gambar 2. Perancangan Menu Bermain

\subsubsection{Spesifikasi Kebutuhan Game Fungsional (SRS Functional)}

Spesifikasi kebutuhan game fungsional pada Game English For Fun adalah seperti ditunjukkan pada tabel. 1:

Tabel 1. Spesifikasi Kebutuhan Game Fungsional (SRS Functional)

\begin{tabular}{ccc}
\hline Kode FR & Keterangan & Aktor \\
\hline FR01 & Menampilkan Menu Utama & Pemain \\
FR02 & Menampilkan Pilihan Kategori & Pemain \\
FR03 & Menampilkan Tutorial & Pemain \\
FR04 & Menampilkan Tentang & Pemain \\
FR05 & Menampilkan Game 1 & Pemain \\
FR06 & Menampilkan Game 2 & Pemain \\
FR07 & Menampilkan Pembelajaran & Pemain \\
FR08 & Menampilkan Pop-up & Pemain \\
FR09 & Menerima input pilihan menu utama & Pemain \\
FR10 & Menerima input pilihan kategori & Pemain \\
FR11 & Keluar dari aplikasi & Pemain \\
FR12 & Menerima input jawaban & Pemain \\
\hline
\end{tabular}

\subsubsection{Flowchart}

Flowchart merupakan gambar yang memperlihatkan urutan dan hubungan antar proses beserta instruksi. Dengan adanya flowchart urutan game menjadi lebih jelas. Penggambaran flowchartGame English For Fun dapat dilihat pada gambar 3 :

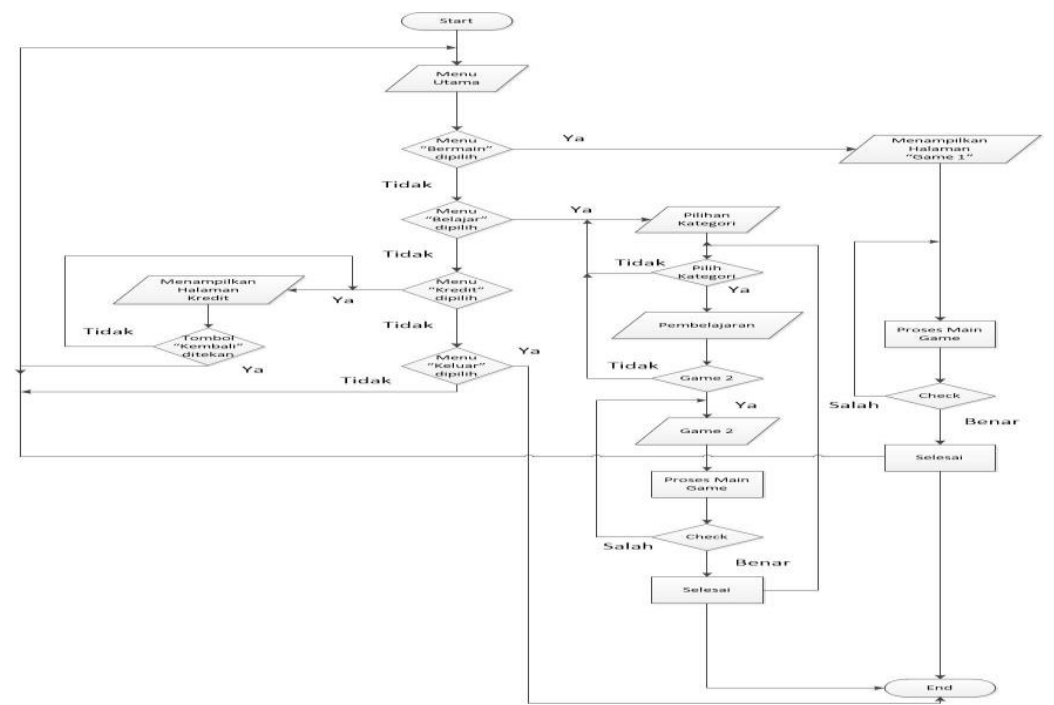

\subsection{Implementasi Dan Evaluasi Game}

Gambar 3. Flowchart

Pada Game English For Fun ini memiliki 3 environment yang berbeda yaitu dengan menggunakan 3 background yang berbeda, namun dengan 1 tema yang sama, yaitu tema pemandangan. Object-object yang berada pada puzzle dominan menggunakan warna-warna cerah seperti biru, hijau, kuning dan merah muda dengan tujuan agar terlihat lebih menarik dan jelas oleh pemain. Implementasi lingkungan pada Game English For Fun dapat dilihat pada gambar 4 . 

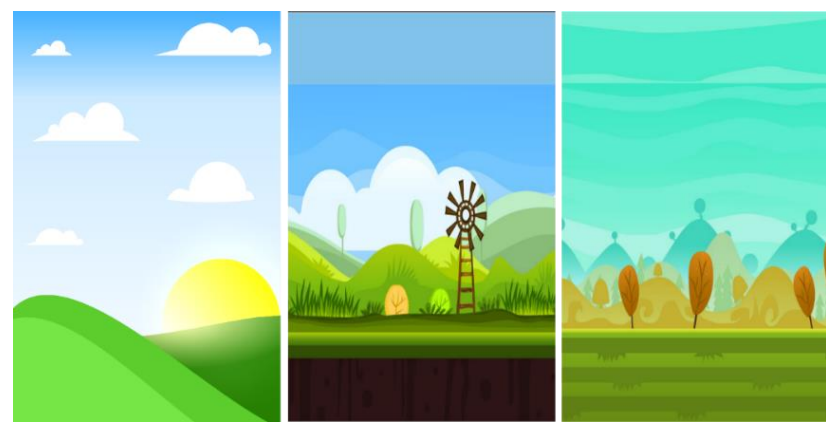

Gambar 4. Implementasi Lingkungan

Level pada Game English For Fun hanya terdapat 1 level, akan tetapi terdapat 2 permainan dengan misi pemain dapat melengkapi kata ejaan membaca yang sebagian hurufnya hilang dengan puzzle huruf yang tersedia pada game 1 dan pemain dapat mencocokan antara gambar dengan puzzle nama bahasa inggris dari kategori tertentu yang telah tersedia pada game 2 sampai benar. Pada setiap game terdapat 4 tahap permaian, dimana puzzle yang harus dijawab jumlahnya akan semakin banyak.

\subsubsection{Implementasi Daftar Misi, Desain Level, Penempatan Dan Pertemuan Game English For Fun "Game1" Dapat Dilihat Pada Gambar 5}

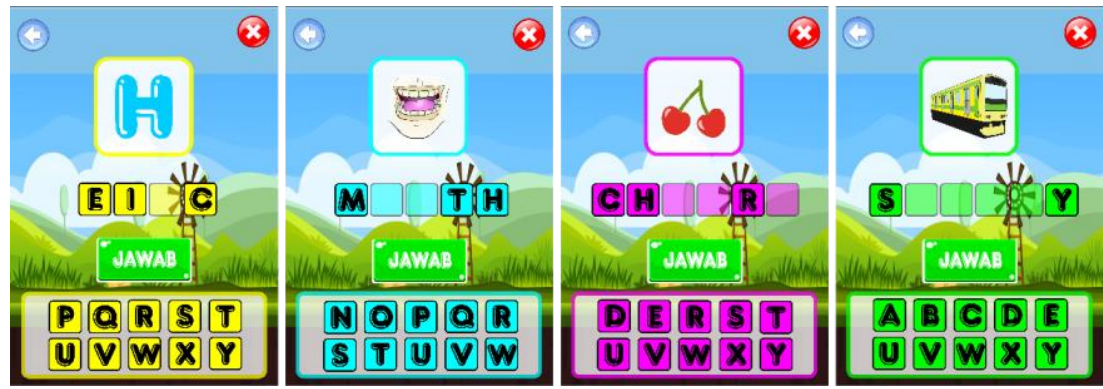

Gambar 5. Implementasi Daftar Misi, Desain Level, Penempatan dan Pertemuan Game1

\subsubsection{Pengujian Blackbox}

Tabel 2. Detail perangkat penguji

\begin{tabular}{cccc}
\hline Spesifikasi & Lenovo a316i & Advan S5L & Lenovo a7000 \\
\hline OS & 4.2 Jelly Bean & 4.4 .2 Kitkat & 5.0 .2 Lolipop \\
CPU & MTK 6572 1.3 & Quad Core, 1.3 GHz & 8 Core $1.7 \mathrm{GHz}$ \\
& GHz Dual Core & & \\
Internal Storage & 512MB RAM + & 1GB RAM + 8GB & 2GB RAM + 16GB \\
Screen & 4GB ROM & Internal Storage & Internal Storage \\
& 4.0" WVGA (800x & 5.5" (540 x 960 & 5.5" Full HD (1920 x \\
& 480) & pixel) & 1080) IPS \\
\hline
\end{tabular}

Tabel 3. Hasil pengujian

\begin{tabular}{|c|c|c|c|c|c|}
\hline \multirow[b]{2}{*}{ No } & \multirow[b]{2}{*}{ Fungsi } & \multirow[b]{2}{*}{ Jenis } & \multicolumn{3}{|c|}{ Hasil } \\
\hline & & & $\begin{array}{c}\text { Lenovo } \\
\text { a316i }\end{array}$ & $\begin{array}{l}\text { Advan } \\
\text { S5L }\end{array}$ & $\begin{array}{c}\text { Lenovo } \\
\text { a7000 }\end{array}$ \\
\hline 1. & Scene & $\begin{array}{l}\text { Splash Screen, Menu Utama, Puzzle Kata, } \\
\text { Pilihan Kategori, Puzzle Mencocokan } \\
\text { gambar dengan nama kategori. }\end{array}$ & $\sqrt{ }$ & $\sqrt{ }$ & $\sqrt{ }$ \\
\hline 2. & Gameplay & $\begin{array}{l}\text { Drag and drop pada game 1, Drag and drop } \\
\text { pada game } 2\end{array}$ & $\sqrt{ }$ & $\sqrt{ }$ & $\sqrt{ }$ \\
\hline 3. & Sound & 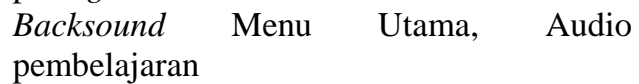 & $\sqrt{ }$ & $\sqrt{ }$ & $\sqrt{ }$ \\
\hline 4. & Button & $\begin{array}{l}\text { Bermain, Belajar, “ } \rightarrow \text { pada akhir } \\
\text { pembelajaran, Kategori, Tentang, Keluar, } \\
\text { " } \leftarrow ", \text { Menu, Mulai, Jawab, “ } \sqrt{ } "\end{array}$ & $\sqrt{ }$ & $\sqrt{ }$ & $\sqrt{ }$ \\
\hline
\end{tabular}


Untuk menguji dan menganalisa game ini sesuai rancangan digunakan pengujian model Blackbox. Pengujian berupa melakukan fungsi-fungsi yang ada apakah sesuai dengan output yang diharapkan dalam tahap perancangan dan implementasi pada kedua perangkat. Pada pengujian ini menggunakan 2 perangkat android yaitu Advan dan Lenovo, detail perangkat penguji dan hasil pengujian dapat dilihat pada tabel 2 dan 3.

Pengujian dilakukan dengan cara membuat table check list yang berisi daftar fungsi-fungsi pada aplikasi kemudian diuji satu persatu lalu diberikan keterangan mengenai hasil test. Data hasil pengujian dapat dilihat pada Tabel. 3.3.

\subsubsection{Kuisioner}

Kuisioner ini untuk melakukan penilaian produk yang telah dibuat oleh responden. Kuisioner terdiri dari 9 pertanyaan yang berhubungan dengan konten dari Game English For Fun. Berikut hasil kuisioner dapat dilihat pada gambar 6 :

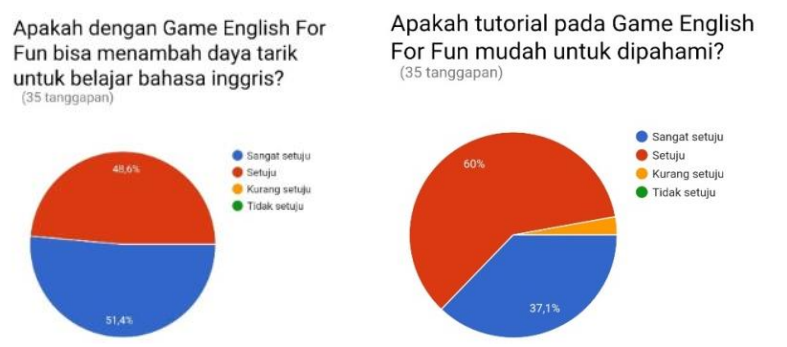

Apakah dengan Game English For Fun dapat lebih mudah dalam belejar bahasa inggris? (35 tanggapan)

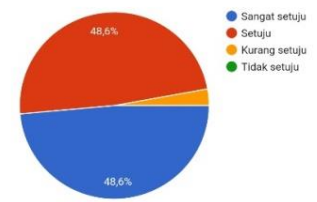

\section{Gambar 6. Hasil kuisoner}

Dari hasil kuisoner responden, tiga pertanyaan yang berkaitan dengan tujuan utama penelitian ini yaitu meyelesaikan masalah belajar bahasa inggris telah tercapai.. Kuisioner dengan pertanyaan "Apakah dengan Game English For Fun dapat lebih mudah dalam belajar Bahasa inggris?" dihasilkan 48,6\% responden menjawab sangat setuju, 48,6\% responden menjawab setuju dan sisanya menjawab kurang setuju. Artinya hampir semua responden setuju bahwa dengan Game English For Fun dapat lebih mudah belajar bahasa inggris.

\section{KESIMPULAN}

Berdasarkan hasil penelitian dan pengujian game ini, dapat mengambil kesimpulan bahwa teknologi pembelajaran yang diterapkan dengan memanfaatkan teknologi smart phone dan perkembangan game, untuk meyelesaikan masalah belajar bahasa inggris telah berhasil dengan parameter kuisoner yang telah dilakukan. Kuisioner dengan pertanyaan "Apakah dengan Game English For Fun dapat lebih mudah dalam belajar bahasa inggris?" dihasilkan 48,6\% responden menjawab sangat setuju, 48,6\% responden menjawab setuju dan sisanya menjawab kurang setuju. Artinya hampir semua responden setuju bahwa dengan Game English For Fun dapat lebih mudah belajar Bahasa inggris.

\section{UCAPAN TERIMA KASIH}

Mengucapkan terima ksaih untuk Prodi D3 Teknik Informatika FMIPA dan LPPM Universitas Sebelas Maret sebagai tempat pengembangan aplikasi Game English For Fun dan support dana pengembangan aplikasi dalam skim pengabdian kepada masyarakat (iBM).

\section{DAFTAR PUSTAKA}

[1] Warsito Bambang, MP 2014, Teknologi Pembelajaran landasan \& aplikasinya, Rineka Cipta.

[2] Sharen Gifary, IKN 2015, 'INTENSITAS PENGGUNAAN SMARTPHONE TERHADAP PERILAKU KOMUNIKASI', Jurnal Sosioteknologi, vol 14, pp. 171-178.

[3] Wijayanti tri Wulan, 2012, MOTIF DAN ADIKSI PEMAIN GAME ONLINE : (STUDI DESKRIPTIF TENTANG MOTIF DAN ADIKSI PEMAIN GAME ONLINE DRAGON NEST DI SURABAYA)', journal.unair.ac.id.

[4] Sahlina dipa ayu, 2015, Pembuatan Game Edukasi Puzzle Qur'an Juz 30 Berbasis Android Menggunakan Unity 3D, Universitas Sebelas Maret.

[5] Nalwan, Agustinus. 1996. Pemrograman Animasi dan Game Profesional 3. Jakarta. Elex Media Komputindo.

[6] Nilwan. 2010. Pemrograman Animasi dan Game Profesional. Jakarta: PT. Gramedia Pustaka Utama.

[7] Ambarwaty, S. (2012). Membagun Aplikasi Pembelajaran Berbasis Multimedia

[8] Sibero, Ivan C, 2010, Membuat Game 2D. Yogyakarta: MediaKom.

[9] Zulkifli. (2013). Model Prediksi Berbasis Neural Network untuk Pengujian Perangkat Lunak Metode Black-Box. Journal Ilmiah, 1. 